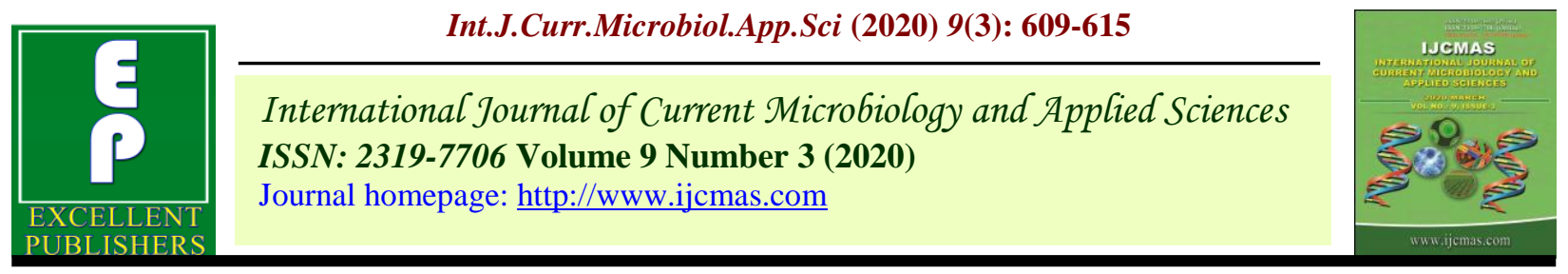

\title{
Prevalence of Gastrointestinal Nematodes in Captive Wild Carnivores of Chhattisgarh, India
}

\author{
S. Chandrakar ${ }^{1}$, J. K. Khutey ${ }^{1}$, S. Roy ${ }^{1}$, J. Singh ${ }^{1 *}$, B. Mishra ${ }^{1}$, K. Jambagi ${ }^{2}$, \\ D. Markandey ${ }^{2}$, S. Meshram ${ }^{2}$, S. L. Ali ${ }^{2}$ and M. Uppal ${ }^{3}$ \\ ${ }^{1}$ Wildlife Health and Forensic Center, ${ }^{2}$ Department of Veterinary Medicine, ${ }^{3}$ Department of \\ Gynacology and Obstetrics, Chhattisgarh Kamdhenu Vishwavidyalaya, \\ Durg-491001, Chhattisgarh, India \\ *Corresponding author
}

\begin{tabular}{|c|}
\hline Keywords \\
\hline $\begin{array}{l}\text { Captive wild } \\
\text { carnivores, } \\
\text { Nematodiasis, } \\
\text { prevalence, Zoos }\end{array}$ \\
\hline Article Info \\
\hline $\begin{array}{l}\text { Accepted: } \\
\text { 05 February } 2020 \\
\text { Available Online: } \\
10 \text { March } 2020\end{array}$ \\
\hline
\end{tabular}

\section{A B S T R A C T}

The aim of this study was to study the prevalence of gastrointestinal nematodes in wild carnivores reared in captive conditions in 03 Zoos of Chhattisgarh. A total of 278 faecal samples of captive wild carnivores were collected which were examined by floatation, sedimentation, McMaster and copro-culture method. Microscopic examination of faecal samples revealed overall prevalence of gastrointestinal nematodiasis in Maitri Bagh Zoo, Bhilai to be $34.78 \%$, Nandanvan Zoo and Safari, Raipur (15.47\%) and Kanan Pendari Zoo, Bilaspur $(29.05 \%)$ respectively. The prevalence of nematode infection in different captive wild carnivores was found to be $22.91 \%, 47.61 \%, 32.85 \%, 13.63 \%, 22.91 \%, 10.52 \%$ and $0 \%$ in lion, leopard, Royal Bengal tiger, hyaena, jackal, fox and jungle cat respectively. Among all 03 zoos under study, overall prevalence of gastrointestinal nematodiasis was highest in Maitri Bagh Zoo, Bhilai followed by Kanan Pendari Zoo, Bilaspur and Nandanvan Zoo and Safari, Raipur respectively. The prevalence of nematode infection in different captive wild carnivores was found to be highest in leopard (47.61\%) followed by Royal Bengal tiger (32.85), lion and jackal (22.91\%), fox (10.52\%) and jungle cat $(0 \%)$ respectively.

\section{Introduction}

An extraordinary climatic diversity is a blessing for India which favors the existence of vast spectrum of species of wild animals and birds (Chhabra et al., 2013). But now-adays due to climate change, habitat destruction, overexploitation of natural resources overall environmental degradation are causing great threat to wildlife and hence various species have been listed as endangered.

Captive wild animals are also affected by various infectious and non-infectious diseases (Thawait et al., 2014). Ecto and endo 
parasites alter the health status of wild animals either directly or indirectly (Bliss, 2009) and any changes in animal's living conditions or environment like from ex situ to in situ, influence the animal's ecology and may increase their sensitivity to the diseases, especially to parasitic infections (Goossens et al., 2005). Unnatural and stressful environment of captive wild animals makes them immunocompromised, there is disturbance in the balance between hostparasite relationships as a result the animal is infected with parasitic diseases that may have a favorable or unfavorable prognosis (Van et al., 2011).

The family canidae is most important host for a large number of parasites, among all wild carnivores (Joshi, 1991). Tapeworm infection can be acquired by consuming raw or undercooked meat in case of humans (Masters, 2018). The same condition can be applied for captive wild carnivores.

Data of parasitic diseases of wildlife are still on the base line (Islam, 2006). Scanning of literature reveals few reports for prevalence of gastrointestinal parasites of captive wild animals of different states of India but it is absolutely silent about the gastrointestinal parasite infection in captive wild animals of Chhattisgarh.

\section{Materials and Methods}

\section{Study area}

All zoological parks (03) of Chhattisgarh viz., Maitri Bagh Zoo, Bhilai, Nandanvan Zoo and Safari, Raipur and Kanan Pendari Zoo, Bilaspur.

\section{Faecal samples}

A total of 278 faecal samples of captive wild carnivores were collected during summer and pre-monsoon ( $\mathrm{n}=139$ each) from all 03 zoos of Chhattisgarh. Samples collected from different wild carnivores namely Asciatic lion (Panthera leo persica) $(\mathrm{n}=24)$, Royal Bengal Tiger (Panthera tigris tigris) $(\mathrm{n}=35)$, Leopard (Panthera pardus) ( $\mathrm{n}=21)$, Jackal (Canis aureus $) \quad(\mathrm{n}=24)$, Hyaena (Hyaena hyaena) $(\mathrm{n}=11)$, Fox (Vulpes bengalensis) $(\mathrm{n}=19)$ and Jungle Cat (Felis chaus) $(\mathrm{n}=05)$ for each season.

The faecal samples were collected in a plastic bag, kept in ice box and brought to the laboratory for qualitative and quantitative examination.

\section{Floatation method}

About $3 \mathrm{~g}$ of faecal sample was taken into a pestle and mortar. A suspension of the sample was made by adding water, followed by complete mixing. The mixed sample was strained with a tea strainer and the strained material was taken into a centrifuge tube and centrifuged at $2000 \mathrm{rpm}$ for 5 minutes. The supernatant were poured off and tube was again refilled with water and centrifuged for 2-3 occasions until the supernatant was cleared. The sediment was mixed with saturated sugar solution $(10 \mathrm{ml})$ in a centrifuge tube and again centrifuged. A drop of the fluid was taken on a clean, dry glass slide from the top layer of fluid and examined under low power (10X) of the microscope after putting a cover slip.

\section{Sedimentation method}

About $3 \mathrm{~g}$ of faecal sample was triturated with water in a pestle and mortar, and was mixed well with water $(15 \mathrm{ml})$ and emulsion was filtered through a tea strainer into a centrifuge tube and centrifuged at $2000 \mathrm{rpm}$ for 5 minutes after which the supernatant was discarded and tube was again refilled with water and centrifuged for 2-3 occasions until 
the supernatant was cleared. The sediment was examined on a glass slide for the presence of parasitic eggs under the low power $(10 \mathrm{X})$ of the microscope after putting a cover slip.

\section{McMaster method}

For small carnivores: About 2 gm of faecal sample was poured into a beaker with $20 \mathrm{ml}$ of water and it was left for soaking for 30 minutes. The whole sample was taken into the pestle and mortar and was mixed thoroughly. The sample was poured back into the same beaker. $40 \mathrm{ml}$ of saturated salt solution was added and mixed thoroughly without forming bubbles (Dilution factor is 1 in 30). One ruled chamber of the Modified McMaster Slide was charged and all eggs were counted under microscope (Number of eggs counted x 100).

For large carnivores: About 3gm of faecal sample was poured into a beaker with $20 \mathrm{ml}$ of water and it was left for soaking for 30 minutes. The whole sample was taken into the pestle and mortar and was mixed thoroughly. The sample was poured back into the same beaker and $40 \mathrm{ml}$ of saturated salt solution was added and mixed thoroughly without forming bubbles (Dilution factor is 1 in 20). One ruled chamber of the Modified McMaster Slide was charged and all eggs were counted under microscope (Number of eggs counted $\mathrm{x}$ $10)$.

\section{Severity of infection}

The level of severity of infection was graded based on EPG into three categories viz.; mild $(+)$ below 500, moderate $(++)$ between 500 to 1000 and severe (+++) more than 1000 (Ghoke et al., 2012).

\section{Copro-culture}

Faecal samples found to be positive for endoparasitic infestation were triturated in pestel and mortar and consistency of the sample was maintained with the help of sprinkling the water in the dried faeces. The material was placed in a glass jar and covered with aluminum foil. The foil was pierced to maintain the air flow for proper aeration. The sample was kept at $27 \pm 1^{\circ} \mathrm{C}$ in the incubator and was examined regularly after 4 th day to harvest the infective third stage larvae (L3). Regular sprinkling of water and stirring the faecal culture was carried out to avoid the growth of fungus and drying. The larvae were then recovered using Baermann's apparatus.

\section{Results and Discussion}

\section{Zoo wise prevalence}

The findings of zoo wise prevalence of gastro-intestinal nematodes in captive wild carnivores have been represented in table no.1.

A total of 278 samples were examined, out of which 46 samples were collected from Maitri Bagh Zoo, Bhilai, 84 samples from Nandanvan Zoo and Safari, Raipur and 148 samples from Kanan Pendari Zoo, Bilaspur during the study period.

Out of 46 samples from Maitri Bagh Zoo, Bhilai 16 (16/46) samples were found to be positive while out of 84 faecal samples from Nandanvan Zoo and Safari, Raipur 13 (13/84) samples were positive and out of 148 samples from Kanan Pendari Zoo, Bilaspur 43 (43/148) samples revealed presence of nematode infection. Hence, zoo wise prevalence was recorded to be $34.78,15.47$ and $29.05 \%$ in Maitri Bagh Zoo, Bhilai, Nandanvan Zoo and Safari, Raipur and Kanan Pendari Zoo, Bilaspur respectively.

Comparison between different zoos reveled that significantly $(\mathrm{P}<0.05)$ higher prevalence $(34.78 \%)$ of gastrointestinal nematodiasis was recorded in captive wild animals of Maitri 
Bagh Zoo, Bhilai followed by 29.05 and $15.47 \%$ prevalence in Kanan Pendari Zoo, Bilaspur and Nandanvan Zoo and Safari, Raipur respectively.

\section{Species wise prevalence}

The findings of species wise prevalence of gastro-intestinal nematodes in captive wild carnivores have been represented in table no.2.

A total of 278 faecal samples were examined out of which 48 samples were collected from lion, 42 samples were collected from leopard, 70 samples were collected from Royal Bengal tiger, 22 samples were collected from hyaena, 48 samples were collected from jackal, 38 samples were collected from fox and 10 samples were collected from jungle cat. Out of 48 samples of lion 11(11/42), 42 samples of leopard 20 (20/42), 70 samples of Royal Bengal tiger 23 (23/70), 22 samples of hyaena $3(3 / 22)$, 48 samples of jackal 11(11/48), 38 samples of fox, $4(4 / 38)$ and 10 samples of jungle cat $0(0 / 10)$ were found to be positive for nematode infection. Hence, the prevalence of nematode infection in different species was found to be $22.91 \%, 47.61 \%, 32.85 \%$, $13.63 \%, 22.91 \%, 10.52 \%$ and $0 \%$ in lion, leopard, Royal Bengal tiger, hyaena, jackal, fox and jungle cat respectively.

Table.1 Zoo wise prevalence (\%) of GI nematodiasis in captive wild carnivores

\begin{tabular}{|l|c|c|c|}
\hline Zoo & $\begin{array}{c}\text { Number of faecal } \\
\text { samples examined }\end{array}$ & $\begin{array}{c}\text { Number of positive } \\
\text { samples }\end{array}$ & $\begin{array}{c}\text { Prevalence } \\
(\%)\end{array}$ \\
\hline $\begin{array}{l}\text { Maitri Bagh Zoo, Bhilai } \\
\text { (MBZ) }\end{array}$ & 46 & 16 & 34.78 \\
\hline $\begin{array}{l}\text { Nandanvan Zoo and } \\
\text { Safari, Raipur (NVZ\&S) }\end{array}$ & 84 & 13 & 15.47 \\
\hline $\begin{array}{l}\text { Kanan Pendari Zoo, } \\
\text { Bilaspur (KPZ) }\end{array}$ & 148 & 43 & 29.05 \\
\hline
\end{tabular}

Table.2 Species wise prevalence (\%) of GI nematodiasis in different carnivore species

\begin{tabular}{|l|l|l|l|}
\hline & $\begin{array}{l}\text { Total no. of } \\
\text { Samples examined }\end{array}$ & $\begin{array}{l}\text { No. of positive } \\
\text { Samples }\end{array}$ & $\begin{array}{l}\text { Prevalence } \\
(\%)\end{array}$ \\
\hline $\begin{array}{l}\text { Lion } \\
\text { (Panthera leo persica) }\end{array}$ & 48 & 11 & 22.91 \\
\hline $\begin{array}{l}\text { Leopard } \\
\text { (Panthera pardus) }\end{array}$ & 42 & 20 & 47.61 \\
\hline $\begin{array}{l}\text { Royal Bengal tiger } \\
\text { (Panthera tigris) }\end{array}$ & 70 & 23 & 32.85 \\
\hline $\begin{array}{l}\text { Hyaena } \\
\text { (Hyaena hyaena) }\end{array}$ & 22 & 3 & 13.63 \\
\hline $\begin{array}{l}\text { Jackal } \\
\text { (Canis aureus) }\end{array}$ & 48 & 11 & 22.91 \\
\hline $\begin{array}{l}\text { Fox } \\
\text { (Vulpes bengalensis) }\end{array}$ & 38 & 4 & 10.52 \\
\hline $\begin{array}{l}\text { Jungle Cat } \\
\text { (Felis chaus) }\end{array}$ & 10 & Nil & 0 \\
\hline
\end{tabular}




\section{Zoo wise prevalence}

The prevalence $(15.47 \%)$ of nematode infection in Nandanvan Zoo and Safari, Raipur is in contrast with the findings of Thawait et al., (2014) who have reported prevalence of helminthic infection in carnivores to be $45.2 \%$ in Nandanvan Zoo, Raipur, Chhattisgarh. However, the findings of our study revealed $29.05 \%$ prevalence of nematode infection in Kanan Pendari Zoo, Bilaspur is similar to the findings of Thawait et al., (2014) who have reported prevalence of helminthic infection in carnivores to be 28.33\% in Kanan Pendari Zoo, Bilaspur, Chhattisgarh.

\section{Species wise prevalence}

The findings of our study indicated that lion showed prevalence of $22.91 \%$ for nematode infection which is much lower as compared to the findings of Chandranaik et al., (2008) who found out the prevalence of $56.3 \%$ of $T$. leonina eggs in lion population at Bannerghatta Biological Park, Banglore. Deshmukh et al., (2009) have also reported much higher prevalence of $57.14 \%$ of helminthic infection in lions at Van Vihar National Park, Bhopal (M.P.). However, Singh et al., (2006) found out the prevalence of $92 \%$ of helmithic eggs or oocysts of protozoa in lions at Mahendra Choudhary Zoological Park, Punjab.

The leopard showed the prevalence of $47.61 \%$ for nematode infection which is in accordance with the findings of Singh et al., (2006) who have reported prevalence of $50 \%$ of helmithic eggs or oocysts of protozoa in leopards at Mahendra Choudhary Zoological Park, Punjab. However, Deshmukh et al., (2009) have reported somewhat higher prevalence of $58.82 \%$ of helminthic infection in leopards at Van Vihar National Park, Bhopal (M.P.).

Royal Bengal tiger recorded the prevalence of
$32.85 \%$ for nematode infection which is lower than the findings of Deshmukh et al., (2009) who have reported prevalence of 50\% of helminthic infection in tigers at Van Vihar National Park, Bhopal (M.P.). However, Singh et al., (2006) found out the prevalence of $45.90 \%$ of helmithic eggs or oocysts of protozoa in tiger at Mahendra Choudhary Zoological Park, Punjab.

The jackal showed prevalence of $22.91 \%$ for nematode infection which is lower than the findings of Singh et al., (2006) who found out the prevalence $100 \%$ of helmithic eggs or oocysts of protozoa in jackal at Mahendra Choudhary Zoological Park, Punjab.

The fox showed the prevalence of $10.52 \%$ for nematode infection which is lowerthan to the findings of Ghoshal et al., (1988) who found out the 4/7 Vulpes vulpes were positive for helminths including Toxascaris leonina, Toxocara cati, T. canis, Ancylostoma tubaeforme and A. caninum at Kamla Nehru Park, Madhya Pradesh, India.

Ii is concluded, among 03 different zoos under study, overall prevalence of gastrointestinal nematodiasis was highest in Maitri Bagh Zoo, Bhilai (34.78\%) followed by Kanan Pendari Zoo, Bilaspur (29.05\%) and Nandanvan Zoo and Safari, Raipur $(15.47 \%)$ respectively. The prevalence of gastrointestinal nematodiasis in different species of captive wild carnivores was evaluated on the basis of faecal sample examination performed on 48 samples collected from lion, 42 samples collected from leopard, 70 samples collected from Royal Bengal tiger, 22 samples collected from hyaena, 48 samples collected from jackal, 38 samples collected from fox and 10 samples collected from jungle cat. The findings of faecal sample examination revealed that 11 samples out of 48 samples of lion (11/48), 20 samples out of 42 samples of leopard (20/42), 23 samples out of 70 samples of Royal 
Bengal tiger (23/70), 3 samples out of 22 samples of hyaena (3/22), 11 samples out of 48 samples of jackal (11/48), 4 samples out of 38 samples of fox (4/38) and none sample out of 10 samples of jungle cat $(0 / 10)$ were found to be positive for nematode infection. Hence, the prevalence of nematode infection in different captive wild carnivores was found to be $22.91 \%, 47.61 \%, 32.85 \%, 13.63 \%$, $22.91 \%, 10.52 \%$ and $0 \%$ in lion, leopard, Royal Bengal tiger, hyaena, jackal, fox and jungle cat respectively.

\section{Acknowledgement}

The authors are grateful to Principal Chief Conservator of Forest (Wildlife), Chhattisgarh, for kind permission for undertaking this work. Authors are also thankful to Veterinary Assistant Surgeon Maitri Bagh Zoo, Bhilai, Nandanvan Zoo and Safari, Raipur and Kanan Pendari Zoo, Bilaspur and Dean, College of Veterinary Science and Animal Husbandry, Anjora, Durg for providing necessary facilities and funds to carry out the present research work.

\section{References}

Bliss, H. 2009. The control of gastrointestinal nematodes of hoofed wild life in North America. Mid American Agricultural Research and Wildlife, 53: 593.

Chandranaik, B. M., Das, D., Mamatha, G. S., Harish, B. R., Shivaraj, Renukaprasad, C. and Krishnappa, G. 2008. A study on prevalence of ascarids in lions (Panthera leo). Journal of Veterinary Parasitology, 22:85-86.

Chhabra, M. B. and Pathak, K. M. L. 2013. Parasites and parasitic diseases of wildlife in India. 2. Carnivores and birds. Indian Journal of Animal Sciences, 83: 567-578.

Deshmukh, S. S., Rewatkar, S. G., Agrawal, A. M., Maske, D. M., Bhangale, G. N. and Shrikhande, G. B. 2009. Endoparasitism in wild animals in captivity. Zoo's Print Journal, 24(10): 11.

Ghoshal, S. B., Garg, U. K., Misraulia, K. S. and Jain, P. C. 1988. Helminth parasites in zoo animals of Kamla Nehru Park, Indore, MP. Livestock Advisor. 13(1): 34-36.

Goossens, E., Dorny, P., Boomker, J., Vercammen, F. and Vercruysse, J. 2005. A 12- month survey of the gastrointestinal helminths of antelopes, gazelles and giraffids kept at two zoos in Belgium. Veterinary Parasitology, 127: 303-312.

Islam, S. 2006. Parasites and parasitic diseases of wildlife. Proceedings of XVII $^{\text {th }}$ National Congress of Veterinary Parasitology and National symposium on Strengths, Challenges and Opportunities in Veterinary Parasitology. pp 43-52.

Joshi, B. P. 1991. Wild animal medicine. Oxford and IBH Publishing. p.97

Masters, M. 2018. Health. www.health.com Singh, P., Gupta, M. P., Singla, L. D., Singh, N. and Sharma, D. R. 2006. Prevalance and chemotherapy of gastrointestinal helminthic infections in wild carnivores of Mahendra Choudhury Zoolgoical Park, Punjab. Journal of Veterinary Parasitology, 20: 17-23.

Thawait, V. K, Maiti, S. K. and Dixit, A. A. 2014. Prevalence of gastro-intestinal parasites in captive wild animals of Nandan Van Zoo, Raipur, Chhattisgarh. Veterinary World, 7: 748-751

Van, Wyk, I. C. and Boomker, J. 2011. The prevalence of helminthes in some common antelopes, warthogs and a bushpig in the Limpopo province, South Africa. Parasites of South African Wildlife. XIX, Ondersteport Journal of Veterinary Research, 78: 1-11. 


\section{How to cite this article:}

Chandrakar, S., J. K. Khutey, S. Roy, J. Singh, B. Mishra, K. Jambagi, D. Markandey, S. Meshram, S. L. Ali and Uppal, M. 2020. Prevalence of Gastrointestinal Nematodes in Captive Wild Carnivores of Chhattisgarh, India. Int.J.Curr.Microbiol.App.Sci. 9(03): 609-615. doi: https://doi.org/10.20546/ijcmas.2020.903.072 